\title{
PENGARUH MANAJEMEN PEMASARAN JASA TERHADAP CITRA LEMBAGA PENDIDIKAN DI MADRASAH TSANAWIYAH MA'ARIF CIKERUH JATINANGOR SUMEDANG
}

\author{
Tatang Ibrahim \\ Universitas islam Negeri Sunan Gunung Djati Bandung \\ tatangibra@gmail.com \\ Padilah Umuhani \\ Universitas Islam Negeri Sunan Gunung Djati Bandung \\ padilahumuhani@gmail.com
}

\begin{abstract}
ABSTRAK
Penelitian ini dilatarbelakangi oleh fenomena yang terjadi di MTs Ma'Arif Cikeruh Jatinangor Sumedang bahwa MTs dijadikan sebagai second choice (pilihan kedua) setelah sekolah negeri. Hal ini disebabkan karena adanya sekolah negeri yang berjarak dengan dengan MTs Ma'Arif Cikeruh Jatinangor Sumedang yang menawarkan keunggulan fasilitas, sehingga menyebabkan adanya suatu persaingan yang menjadi tantangan dalam merekrut calon siswa baru. Penelitian ini bertujuan untuk mengetahui manajemen pemasaran jasa dan citra lembaga pendidikan di MTs Ma'Arif Cikeruh Jatinangor Sumedang. Serta apakah terdapat pengaruh antara manajemen pemasaran jasa terhadap citra lembaga pendidikan di MTs Ma'Arif Cikeruh Jatinangor Sumedang. Jenis penelitian yang digunakan dalam penelitian ini adalah kuantitatif lapangan dengan menggunakan metode survey. Teknik pengumpulan data yang digunakan dalam penelitian ini menggunakan angket/kuesioner. Instrument kuesioner dilakukan dengan pengujian validitas dan reliabilitas. Teknik analisis data yang digunakan yaitu uji normalitas, teknik korelasi dan teknik analisis regresi sederhana. Hasil dari penelitian ini menunjukkan bahwa kualitas manajemen pemasaran jasa di MTs Ma'Arif Cikeruh Jatinangor Sumedang termasuk dalam kategori "cukup baik" yaitu berada pada interval 50-54 dengan nilai rata - rata 53,10. Sedangkan kualitas citra lembaga pendidikan di MTs Ma'Arif Cikeruh Jatinangor Sumedang termasuk dalam kategori "cukup baik" yaitu berada pada interval 48 - 52 dengan nilai rata - rata 51,09. Adapun hasil analisisnya secara keseluruhan menunjukkan ada pengaruh yang signifikan antara manajemen pemasaran jasa terhadap citra lembaga pendidikan. Hal ini ditunjukkan dari nilai $F_{\text {hitung }}$ sebesar 81,691. Berdasarkan hasil perhitungan ini, maka hipotesis kerja $\left(H_{1}\right)$ yang berbunyi ada pengaruh yang positif dan signifikan antara manajemen pemasaran jasa terhadap citra lembaga pendidikan di MTs Ma'Arif Cikeruh Jatinangor Sumedang diterima.
\end{abstract}

Kata Kunci: manajemen, pemasaran jasa, citra lembaga pendidikan 


\section{ABSTRACT}

This research was motivated by the phenomenon that occurred at MTs Ma'Arif Cikeruh Jatinangor Sumedang that MTs was used as the second choice (second choice) after public schools. This is due to the fact that there are public schools that are far from MTs Ma'Arif Cikeruh Jatinangor Sumedang which offer superior facilities, thus causing a competition that becomes a challenge in recruiting new students. This study aims to determine the marketing management of services and the image of educational institutions at MTs Ma'Arif Cikeruh Jatinangor Sumedang. And whether there is an influence between service marketing management on the image of educational institutions at MTs Ma'Arif Cikeruh Jatinangor Sumedang. The type of research used in this research is field quantitative using survey method. The data collection technique used in this study used a questionnaire/questionnaire. The questionnaire instrument was carried out by testing the validity and reliability. The data analysis technique used is normality test, correlation technique and simple regression analysis technique. The results of this study indicate that the quality of service marketing management at MTs Ma'Arif Cikeruh Jatinangor Sumedang is included in the "good enough" category, which is in the 50-54 interval with an average value of 53.10. While the image quality of educational institutions at MTs Ma'Arif Cikeruh Jatinangor Sumedang is included in the "good enough" category, which is in the interval 48 - 52 with an average value of 51.09. The results of the overall analysis show that there is a significant influence between service marketing management on the image of educational institutions. This is indicated by the $F_{\text {count }}$ value of 81,691 . Based on the results of this calculation, the working hypothesis $\left(H_{1}\right)$ which reads that there is a positive and significant influence between service marketing management on the image of educational institutions at MTs Ma'Arif Cikeruh Jatinangor Sumedang is accepted.

Key Words: management, service marketing, image of educational institutions

\section{PENDAHULUAN}

Lembaga pendidikan Islam bukan hanya sebagai tempat untuk menuntut ilmu pengetahuan umum dan ilmu agama saja tetapi dituntut untuk memberikan kepuasan pelanggan. Banyak lembaga pendidikan yang bersaing dalam mempromosikan jasa mulai dari jasa kurikuler, jasa penelitian, jasa ekstrakurikuler, jasa pengembangan kehidupan, jasa administrasi, serta jasa layanan khusus agar menarik calon pelangggan yaitu murid, orang tua murid, dan pihak lainnya (Faizin, 2017). Dalam hal ini, maka setiap lembaga pendidikan perlu adanya manajemen pemasaran dengan baik. Manajamen pemasaran merupakan suatu usaha yang diawali dari tahap persiapan, pengorganisasian, penerapan, serta pengawasan atau pengendalian kegiatan pemasaran dalam suatu lembaga agar mencapai tujuan lembaga secara efektif dan efisien.

James A.F Stoner dalam Jahari \& Syarbini (2013) menjelaskan bahwa manajemen merupakan suatu proses yang dimulai dari tahap perencanaan, pengorganisasian, pengarahan, dan pengawasan usaha-usaha para anggota organisasi serta penggunaan sumber daya-sumber daya organisasi lainnya untuk mencapai tujuan yang telah ditetapkan. G. Terry dalam Badrudin (2015) mendefinisikan manajemen merupakan sebuah proses yang diawali dari tahap 
persiapan, pembagian, pelaksanaan, pengawasan yang dilakukan untuk memenuhi target melalui pemanfaatan sumber daya organisasi dan sumber daya lainnya. Irawan (2019) menjelaskan bahwa inti dari manajemen adalah pengelolaan baik dalam organisasi, lembaga atau perkumpulan tertentu. Substansi dari konsep pengelola adalah tindakan dari amnesia itu sendiri. Dengan demikian inti dari manajemen baik di perusahan, organisasi pemerintah maupun lembaga pendidikan adalah tindakan orang-orang yang berada didalamnya (human action).

Menurut Kotler dalam Sudaryono (2016), bahwa pemasaran merupakan suatu sistem sosial dan manajerial di mana seseorang ataupun kelompok akan mendapatkan apa yang mereka perlukan dan inginkan dengan cara pembuatan dan pergantian produk dan nilai satu sama lain. Kotler juga mengemukakan pemasaran mencakup semua kegiatan yang dirancang demi mewujudkan dan memfasilitasi setiap pertukaran untuk memuaskan keperluan dan harapan pelanggan.

Jasa adalah suatu aktivitas yang dipersepsikan secara distingtif yang pada prinsipnya bersifat tidak tersentuh demi memuaskan keperluan dan tidak harus bersifat terikat pada pemasaran barang atau jasa lain (Mursyid, 2014: 116). Kotler dalam Khasanah (2015), mendefinisikan jasa adalah setiap perilaku atau kinerja yang ditawarkan oleh suatu kelompok pada kelompok lainnya yang secara hakikat tidak berbentuk dan tidak mengakibatkan kepindahan kepemilikan.

Pemasaran jasa pendidikan merupakan sebuah metode untuk melakukan sesuatu dimana murid, orang tua murid, guru serta staf Tata Usaha (TU) dan masyarakat menganggap madrasah sebagai lembaga penyokong masyarakat yang berkontribusi demi menyiapkan keperluan konsumen pendidikan. Maka dari itu, pemasaran jasa pendidikan lebih dari sekedar kegiatan penjualan, periklanan, serta promosi demi menciptakan permintaan jasa pendidikan (Wijaya, 2012).

Pemasaran dalam dunia pendidikan berfungsi untuk menciptakan image (citra) yang postif di mata masyarakat dan pelanggan agar masyarakat dapat tertarik dalam memanfatkan jasa yang ditawarkan oleh lembaga pendidikan. Citra merupakan sebuah pandangan/persepsi yang bersumber dari pengetahuan, penjelasan serta pemahaman seseorang mengenai kebenaran informasi (Mulyadi, 2018).

Dewasa ini transformasi dalam dunia pendidikan yang semakin aktif memerlukan pemasaran dalam memasarkan jasa pendidikan, disertai dengan adanya promosi di tengah semakin kompetitifnya dunia pendidikan dalam menawarakan produk jasa pendidikan kepada pelanggannya, juga adanya perubahan lingkungan yang semakin dinamis sehingga sekolah/madrasah harus melaksanakan penilaian diri dalam mnganalisis keberadaannya (Jahari \& Syarbini, 2013, p. 156). Fenomena tersebut diperkuat dengan hasil studi pendahuluan yang dilakukan peneliti di MTs Ma'Arif Cikeruh Jatinangor Sumedang bahwa MTs dijadikan sebagai second choice (pilihan kedua) setelah sekolah negeri. Hal ini disebabkan karena adanya sekolah negeri yang berjarak tidak terlalu jauh dengan dengan MTs Ma'Arif Cikeruh Jatinangor Sumedang yang menawarkan keunggulan fasilitas, sehingga menyebabkan adanya suatu persaingan yang menjadi tantangan dalam merekrut calon siswa baru. Demi 
perkembangan sebuah lembaga, kepala madrasah MTs Ma'Arif Cikeruh Jatinangor Sumedang terus melakukan strategi-strategi pemasaran dengan mengembangkan unsur-unsur pemasaran jasa pendidikan yaitu product, price, place, promotion, people, physical evidence dan process serta melakukan kerjasama dengan pihak Koramil dan Kepolisisan untuk menjaga peserta didik agar tidak melanggar peraturan sekolah.

Dari berbagai layanan jasa yang dimiliki MTs Ma'Arif Cikeruh Jatinangor Sumedang, banyak orang tua yang mengharapkan anaknya bisa bersekolah di sekolah tersebut. Hal ini dapat dilihat setiap tahunnya calon peserta didik yang masuk semakin banyak. Di samping itu juga, MTs Ma'Arif Cikeruh Jatinangor Sumedang dikelola oleh para tenaga pendidik yang profesional yang mempunyai kualifikasi pendidikan S1 dan S2. Berlandaskan latar belakang yang telah dijabarkan di atas, begitu pentingnya manajemen pemasaran jasa dalam suatu lembaga pendidikan, maka dari itu penulis mengadakan penelitian dengan tentang bagaimana pengaruh manajemen pemasaran jasa terhadap citra lembaga pendidikan di MTs Ma'Arif Cikeruh Jatinangor Sumedang.

\section{METODE}

Penelitian ini menggunakan pendekatan kuantitatif. Pendeketan kuantitatif merupakan pendekatan yang menitikberatkan terhadap percobaan teori dengan mengukur variabel penelitian menggunakan bilangan serta melaksankan studi data melalui metode statistic (Suryana, 2015, p. 37). Metode yang digunakan dalam penelitian ini adalah metode survey. Metode survey ialah suatu cara penelitian yang memakai angket sebagai alat pertama guna mendapatkan serta memperoleh informasi yang bertujuan mengkaji antara variabel yang satu dengan variabel lainnya (Sandu \& Sodik, 2015). Penelitian ini menggunakan jenis penelitian kuantitatif lapangan. Penelitian kuantitatif lapangan yaitu sebuah penelitian dengan karakteristik permasalahan yang berkaitan dengan latar belakang dan situasi sekarang ini dari subjek yang akan dikaji, dan hubungannya dengan lingkungan (Suryana, 2015, p. 38).

Pada penelitian ini, sumber datanya yaitu dari populasi dan sampel. Adapun yang menjadi populasi dalam penelitian ini adalah orang tua siswa dari siswa di Mts Ma'Arif Cikeruh Jatinangor Sumedang yang berjumlah 868 siswa dan yang menjadi sampel adalah $10 \%$ dari kuantitas orang tua siswa dari siswa yang bersekolah di MTs Ma'Arif Cikeruh Jatinangor Sumedang pada tahun ajaran 2019/2020 dengan jumlah 868 siswa. Maka sampel 10\% dari jumlah total siswa 868 adalah 86.8 dibulatkan menajdi 87. Maka, orang tua siswa yang dijadikan obyek pada penelitian ini jumlahnya 87 orang.Teknik pengumpulan data yang digunakan pada penelitian ini ialah kuesioner/angket. Kuesioner atau angket ialah instrumen pengumpul data/informasi yang diberikan kepada responden yang dilakukan dengan cara memberikan seperangkat pernyataan dan pertanyaan untuk diisi (Suryana, 2015, p. 228).

Kemudian dilakukan uji coba instrument data yaitu dengan uji validitas dan reliabilitas. Uji validitas merupakan suatu standar yang membuktikan sebuah kategori valid dan shahih suatu alat pengumpul data (Arikunto, 2016). Uji reliabilitas ialah sebuah tingkatan yang menyatakan bahwa instrument yang dipakai memiliki kecakapan sebagai instrument, seperti di ukur kestabilan hasil 
penguraian dari waktu ke waktu apabila kejadian yang diukur tidak beralih (Suryana, 2015, p. 235).

Teknik analisis data yang digunakan yaitu uji normalitas, uji korelasi dan regresi. Uji nomalitas merupakan suatu cara atau tahapan yang dpakai guna mengetahui apakah data yang berasal dari populasi terdistribusi normal atau sedang dalam sebaran normal (Nuryadi et al., 2017, p. 79). Uji korelasi dengan menemukan interelasi data atau korelasi diantara variabel $X$ dengan variabel $Y$ (Sandu \& Sodik, 2015, p. 89). Analisis regresi sederhana merupakan suatu analisis yang dipakai guna mengetahui pengaruh dari variabel bebas (X) terhadap variabel terikat $(\mathrm{Y})$.

\section{HASIL DAN PEMBAHASAN}

Manajemen Pemasaran Jasa di MTs Ma'Arif Cikeruh Jatinangor Sumedang

Dalam penelitian ini manajemen pemasaran jasa di MTs Ma'Arif Cikeruh Jatinangor Sumedang termasuk dalam variabel bebas (X). Pengujian terhadap variabel manajemen pemasaran jasa di MTs Ma'Arif Cikeruh Jatinangor Sumedang dimulai dengan melakukan uji validitas dan uji reliabilitas. Hasil perhitungan dari uji validitas diketahui bahwa semua item soal mengenai variabel manajemen pemasaran jasa dikatakan valid untuk dijadikan sebagai instrumen penelitian. Hal ini berarti seluruh item soal dapat digunakan untuk mengukur manajemen pemasaran jasa di MTs Ma'Arif Cikeruh Jatinangor Sumedang.

Berdasarkan hasil uji reliabilitas manajemen pemasaran jasa diketahui bahwa instrumen manajemen pemasaran jasa di MTs Ma'Arif Cikeruh Jatinangor Sumedang termasuk kategori konsisten. Hal ini berarti jawaban dari responden mengenai kuesioner menunjukkan kekonsistenan sehingga hasil yang didapatkan dari kuesioner tersebut dapat digunakan untuk bisa dianalisis lebih lanjut.

Untuk menentukan nilai kuantitatif manajemen pemasaran jasa yaitu dengan cara menggunakan skor jawaban angket dari responden sesuai dengan frekuensi jawaban. Berdasarkan perhitungan statistik diketahui bahwa manajemen pemasaran jasa di MTs Ma'Arif Cikeruh Jatinangor Sumedang dinilai cukup baik oleh pelangganya dan berada pada interval 50-54 dengan nilai ratarata 53,10.

Hasil perhitungan tersebut mendukung teori yang mengungkapkan bahwa suatu lembaga pendidikan jika ingin mendapatkan keberhasilan dalam jangka panjang, maka lembaga tersebut harus menciptakan layanan yang memuaskan keinginan serta kebutuhan pelanggannya. Guna menciptakan layanan yang memuaskan ini, maka lembaga pendidikan menciptakan bauran pemasaran.

Hasil penelitian tersebut juga sesuai dengan teori yang menyatakan bahwa nilai positif yang akan diterima sekolah/madrasah ketika bisa mewujudkan keperluan serta harapan pelanggannya melalui bauran pemasaran ialah meningkatnya kuantitas peserta didik ini, jumlah guru yang berkualitas, jumlah donatur, partisipasi orang tua, menambah karyawan sekolah yang suka bekerja, adanya dukungan dari masyarakat, serta hubungan yang menguntungkan dengan pelanggan eksternal pendidikan (Wijaya, 2016). 


\section{Citra Lembaga Pendidikan di MTs Ma'Arif Cikeruh Jatinangor Sumedang}

Dalam penelitian ini citra lembaga di MTs Ma'Arif Cikeruh Jatinangor Sumedang termasuk dalam variabel terikat $(\mathrm{Y})$. Pengujian terhadap variabel citra lembaga di MTs Ma'Arif Cikeruh Jatinangor Sumedang dimulai dengan melakukan uji validitas dan uji reliabilitas. Hasil perhitungan dari uji validitas dan diketahui bahwa semua item soal mengenai variabel citra lembaga dikatakan valid untuk dijadikan sebagai instrumen penelitian. Hal ini berarti seluruh item soal dapat digunakan untuk mengukur citra lembaga di MTs Ma'Arif Cikeruh Jatinangor Sumedang.

Berdasarkan hasil uji reliabilitas citra lembaga diketahui bahwa instrumen citra lembaga di MTs Ma'Arif Cikeruh Jatinangor Sumedang termasuk kategori konsisten. Hal ini berarti jawaban dari responden mengenai kuesioner menunjukkan kekonsistenan sehingga hasil yang didapatkan dari kuesioner tersebut dapat digunakan untuk bisa dianalisis lebih lanjut.

Untuk menentukan nilai kuantitatif citra lembaga pendidikan yaitu dengan cara menggunakan skor jawaban kuesioner dari responden sesuai dengan frekuensi jawaban. Berdasarkan hasil perhitungan data statistik dapat diketahui bahwa citra lembaga pendidikan di MTs Ma'Arif Cikeruh Jatinangor Sumedang dinilai cukup baik oleh masyarakat penggunanya dan berada pada interval 48-52 dengan nilai rata-rata 51,09.

Hasil perhitungan tersebut sesuai dengan teori yang menjelaskan bahwa citra merupakan suatu pandangan/anggapan yang didapatkan berdasarkan pengetahuan, pengertian, dan pengalaman seseorang mengenai fakta/kebenaran (Mulyadi, 2018). Image yang tampak baik dari suatu lembaga akan baik bagi lembaga pendidikan tersebut, sedangkan image yang buruk akan berdampak merugikan terhadap sebuah lembaga tersebut (Sarifudin \& Maya, 2019).

Citra juga merupakan sesuatu yang harus diperjuangkan dan dipertahankan secara terus menerus sepanjang masa. Citra tergolong kegiatan pemasaran dalam memposisikan bagaimana madrasah ditempatkan oleh pelanggan, apakah murah tapi bermutu, kreatif-inovatif, atau mahal-produktif. Maka dari itu, membangun citra sekolah/madrasah memerlukan waktu panjang serta adanya komitmen dari seluruh elemen sekolah/madrasah (Asmani, 2015).

\section{Pengaruh Manajemen Pemasaran Jasa terhadap Citra lembaga Pendidikan di MTs Ma'Arif Cikeruh Jatinangor Sumedang}

Perhitungan ini dilakukan untuk menguji mengenai ada tidaknya pengaruh variabel $X$ dan variabel $Y$ yaitu pengaruh manajemen pemasaran jasa terhadap citra lembaga pendidikan di MTs Ma'Arif Cikeruh Jatinangor Sumedang. Untuk perhitungannya menggunakan uji korelasi Pearson, untuk hasil pengujian korelasi ini menggunakan bantuan program SPSS versi 20. Adapun hasil perhitungannya adalah sebagai berikut. 
Tabel 1. Hasil Uji Korelasi Variabel X (Manajemen Pemasaran Jasa) dan Variabel $Y$ (Citra Lembaga)

\begin{tabular}{|c|c|c|c|}
\hline & & $\begin{array}{c}\text { Manajemen } \\
\text { Pemasaran Jasa } \\
\text { (Variabel X) }\end{array}$ & $\begin{array}{c}\text { Citra } \\
\text { Lembaga } \\
\text { (Variabel Y) }\end{array}$ \\
\hline \multirow{3}{*}{$\begin{array}{c}\text { Manajemen } \\
\text { Pemasaran Jasa } \\
(\text { Variabel X) }\end{array}$} & Pearson Correlation & 1 & $.700^{* *}$ \\
\hline & Sig. (2-tailed) & & .000 \\
\hline & $\mathrm{N}$ & 87 & 87 \\
\hline \multirow{3}{*}{$\begin{array}{c}\text { Citra Lembaga } \\
\text { (Variabel Y) }\end{array}$} & Pearson Correlation & $.700^{* *}$ & 1 \\
\hline & Sig. (2-tailed) & .000 & \\
\hline & $\mathrm{N}$ & 87 & 87 \\
\hline
\end{tabular}

Dari hasil perhitungan korelasi di atas, diperoleh koefisen korelasi $r_{x y}$ sebesar 0,700 . Selanjutnya hasil perhitungan $r_{x y}$ dikonsultasikan dengan $r_{\text {tabel }}$ dengan $\mathrm{N}$ sebesar 87 dari taraf signifikansi $5 \%$ ( $r_{\text {tabel }}$ sebesar 0,208$)$ dan pada taraf signifikansi $1 \%\left(r_{\text {tabel }}\right.$ sebesar 0,271$)$ dengan kriteria pengujinya adalah jika $r_{x y}>r_{\text {tabel }}(0,700>0,208$ dan 0,271$)$. Hasil perhitungan tersebut dapat disimpulkan bahwa ada korelasi yang positif antara manajemen pemasaran jasa terhadap citra lembaga pendidikan di MTs Ma'Arif Cikeruh Jatinangor Sumedang.

Selain itu diketahui juga bahwa tingkat korelasi manajemen pemasaran jasa terhadap citra lembaga pendidikan di MTs Ma'Arif Cikeruh Jatinangor Sumedang sebesar 0,700 termasuk dalam kategori kuat karena terletak pada interval 0,60-0,799.

Langkah berikutnya adalah melakukan analisis regresi sederhana. Sebelum mencari nilai $F$, maka ditentukan terlebih dahulu taraf signifikansinya (level of significant). Dalam penelitian ini menggunakan taraf signifikan $a=5 \%$ dan $1 \%$ dengan derajat kebebasan pembilang 1 , maka diperoleh $\mathrm{F}_{\text {tabel }} 5 \%$ sebesar 3,95 dan $\mathrm{F}_{\text {tabel }} 1 \%$ sebesar 6,94. Setelah taraf signifikan $\mathrm{F}_{\text {tabel }}$ dalam penelitian ini diketahui, maka langkah selanjutnya adalah mencari harga $F$ dengan menggunakan aplikasi SPSS versi 20. Adapun hasil perhitungannya adalah sebagai berikut.

Tabel 2. Hasil Perhitungan Uji F

\begin{tabular}{lccccc}
\hline Model & $\begin{array}{c}\text { Sum of } \\
\text { Squares }\end{array}$ & Df & $\begin{array}{c}\text { Mean } \\
\text { Square }\end{array}$ & F & Sig. \\
\hline Regression & 1371.749 & 1 & 1371.749 & 81.691 & $.000^{\mathrm{b}}$ \\
\hline Residual & 1427.308 & 85 & 16.792 & & \\
\hline Total & 2799.057 & 86 & & & \\
\hline
\end{tabular}

Sumber: Pengolahan data dengan SPSS versi 20, 2020

Dari hasil analisis uji hipotesis melalui aplikasi SPSS versi 20 nilai $F$ telah diketahui sebasar 81,691 dengan derajat kebebasan pembilang 1 dari $(\mathrm{N}-2=$ 
$87-2=85)$, maka diperoleh $\mathrm{F}=81,691>\mathrm{F}_{\text {tabel }} 5 \%=3,95$ dan $\mathrm{F}=81,691>$ $\mathrm{F}_{\text {tabel }} 1 \%=6,94$. Hal ini berarti manajemen pemasaran jasa secara simultan (menyeluruh) mempunyai pengaruh yang signifikan terhadap citra lembaga pendidikan di MTs Ma'Arif Cikeruh Jatinangor Sumedang. Selanjutnya adalah mencari sumbangan efektif dari manajemen pemasaran jasa terhadap citra lembaga pendidikan dengan mencari koefisien determinasi ( $R$ square) terlebih dahulu dengan menggunakan aplikasi SPSS versi 20. Adapun hasil perhitungannya adalah sebagai berikut.

Tabel 3. Hasil Perhitungan Koefisien Determinasi

\begin{tabular}{ccccc}
\hline Model & R & R Square & $\begin{array}{c}\text { Adjusted R } \\
\text { Square }\end{array}$ & $\begin{array}{c}\text { Std. Error of } \\
\text { the Estimate }\end{array}$ \\
\hline 1 & $.700^{\mathrm{a}}$ & .490 & .484 & 4.098 \\
\hline
\end{tabular}

Sumber: Pengolahan data dengan SPSS versi 20, 2020

Berdasarkan hasil perhitungan $\mathrm{R}$ square di atas, diperoleh koefisien determinasi $R=0,490$. Hasil tersebut menunjukkan bahwa sumbangan efektif dari manajemen pemasaran jasa terhadap citra lembaga pendidikan adalag 49 $\%$ dan sisanya sebesar $51 \%$ dipengaruhi oleh faktor-faktor lain yang bukan menjadi fokus pembahasan dalam penelitian ini. Hasil penelitian tersebut sesuai dengan teori dari Alma (2011) yang menjelaskan bahwa sekolah/madrasah yang mau berhasil dalam menggapai cita-citanya perlu menerapkan manajemen pemasaran jasa dalam menghadapi berbagai karakter/sifat pelanggan yang bermacam-macam karena akan berpengaruh terhadap peningkatan image sekolah serta kuantitas peserta didik yang dikehendaki. MTs Ma'Arif Cikeruh Jatinangor Sumedang juga selalu berusaha memenuhi kebutuhan, keinginan serta harapan pelanggan jasa pendidikan dengan meningkatkan kualitas produk, biaya pendidikan yang terjangkau tapi berkualitas, lokasi yang strategis, aman serta nyaman, promosi yang menarik, sumber daya manusia yang memiliki kompetensi, saranan dan prasarana yang memadai, serta proses pendidikan yang dinamis.

\section{SIMPULAN}

Berdasarkan hasil penelitian dan pembahasan yang dipaparkan sebelumnya, maka dapat ditarik simpulan bahwa manajemen pemasaran jasa di MTs Ma'Arif Cikeruh Jatinangor Sumedang dinilai cukup baik oleh masyarakat. Hal ini sejalan dengan teori yang menyatakan bahwa sebuah lembaga pendidikan jika ingin mendapatkan keberhasilan dalam jangka panjang, maka lembaga tersebut harus menciptakan layanan yang memuaskan kebutuhan serta keinginan pelanggannya. Citra lembaga pendidikan di MTs Ma'Arif Cikeruh Jatinangor Sumedang dinilai cukup baik oleh masyarakat penggunanya dan sesuai dengan teori yang menyatakan bahwa citra merupakan sebuah kesan yang diperoleh berdasarkan pengetahuan, pengertian, dan pengalaman seseorang mengenai fakta-fakta atau kenyataan.

Secara keseluruhan manajemen pemasaran jasa terhadap citra lembaga pendidikan mempunyai pengaruh yang signifikan di MTs Ma'Arif Cikeruh 
Jatinangor Sumedang. Manajemen pemasaran jasa mempunyai pengaruh terhadap citra lembaga pendidikan karena nilai dari hasil uji $\mathrm{F}$ sebesar 81,691 lebih besar dari nilai level of significant yang ditentukan yaitu $5 \%$ sebesar 3,95 dan $1 \%$ sebesar 6,94. Selanjutnya berdasarkan perhitungan $\mathrm{R}$ square, diperoleh koefisien determinasi $R=0,490$. Hasil tersebut menunjukkan bahwa sumbangan efektif manajemen pemasaran jasa terhadap citra lembaga pendidikan di MTs Ma'Arif Cikeruh Jatinangor Sumedang adalah sebesar $49 \%$ dan sisanya sebesar $51 \%$ dipengaruhi oleh faktor-faktor lain yang bukan menjadi fokus pembahasan dalam penelitian ini. Dengan demikian hipotesis kerja $\left(\mathrm{H}_{1}\right)$ yang berbunyi ada pengaruh yang positif dan signifikan antara manajemen pemasaran jasa terhadap citra lembaga pendidikan di MTs MA'Arif Cikeruh Jatinangor Sumedang diterima.

\section{REFERENSI}

Alma, B. (2011). Pemasaran Stratejik Jasa Pendidikan. Alfabeta.

Arikunto, S. (2016). Prosedur Penelitian: Suatu Pendekatan Praktik. Rineka Cipta.

Asmani, J. M. (2015). Manajemen Efektif Marketing Sekolah: Strategi Menerapkan Jiwa Kompetisi dan Sportivitas untuk Melahirkan Sekolah Unggulan. DIVA Press.

Badrudin, B. (2015). Dasar-Dasar Manajemen. Alfabeta.

Faizin, I. (2017). Strategi Pemasaran Jasa Pendidikan dalam Meningkatkan Nilai Jual Madrasah. Madaniyah, 7(2), 261-283.

https://journal.stitpemalang.ac.id/index.php/madaniyah/article/view/15/1

Irawan. (2019). Filsafat Manajemen Pendidikan Islam. PT Remaja Rosdakarya.

Jahari, J., \& Syarbini, A. (2013). Manajemen Madrasah: Teori, Strategi, dan Implementasi. Alfabeta.

Khasanah, A. (2015). Pemasaran Jasa Pendidikan Sebagai Strategi

Peningkatan Mutu Di SD Alam Baturraden. El-Tarbawi, 8(2), 161-176. https://doi.org/10.20885/tarbawi.vol8.iss2.art4

Mulyadi, S. (2018). Perencanaan Humas Dan Usaha Membangun Citra Lembaga Yang Unggul. TADBIR: Jurnal Studi Manajemen Pendidikan, 2(2), 121-134. https://doi.org/10.29240/jsmp.v2i2.566

Mursyid, M. (2014). Manajemen Pemasaran. PT. Bumi Aksara.

Nuryadi, N., Astuti, T. D., Utami, E. S., \& Budiantara, M. (2017). Dasar-Dasar Statistik Penelitian. Gramasurya.

Sandu, S., \& Sodik, M. A. (2015). Dasar Metodologi Penelitian. Literasi Media Publishing.

Sarifudin, S., \& Maya, R. (2019). Implementasi Manajemen Pemasaran Jasa Pendidikan Dalam Meningkatkan Kepuasan Pelanggan Di Madrasah Aliyah Terpadu (MAT) Darul Fallah Bogor. Islamic Management: Jurnal Manajemen Pendidikan Islam, 2(2), 135-154.

https://doi.org/10.30868/im.v2i02.513

Sudaryono. (2016). Manajemen Pemasaran Teori dan Aplikasi. PT. Andi Offset. Suryana, Y. (2015). Metode Penelitian Manajemen Pendidikan. CV Pustaka Setia.

Wijaya, D. (2012). Pemasaran Jasa Pendidikan: Mengapa Sekolah Memerlukan Marketing. Salemba Empat. 
T. Ibrahim, P. Umuhani

Wijaya, D. (2016). Pemasaran Jasa Pendidikan. Bumi Aksara. 